\title{
Study on Professional (Group) Leaders in Higher Vocational Education
}

\author{
Lixin Tan ${ }^{1,2, *}$, Cheng Xiao ${ }^{1}$, Zhi Lv ${ }^{2,3}$ \\ ${ }^{1}$ School of Electronic Engineering, Hunan College of Information, Changsha, China, 410200 \\ ${ }^{2}$ School of Intelligent and Information, Hunan Agricultural University, Changsha, China, 410128 \\ ${ }^{3}$ Changsha High Tech Engineering School, Changsha, China, 410108 \\ *Corresponding author
}

\begin{abstract}
\section{INTRODUCTION}

The construction of professional (Group) leaders is an extremely important aspect of the construction of professional (Group) and teaching team in higher vocational education. An excellent professional (Group) leader is a flag, a direction, and a key factor determining the development and construction quality of a professional (Group). But what are the professional (Group) leaders? What should professional (Group) leaders do? What do professional (Group) leaders do? There are different definitions and responsibilities in different schools. This paper takes the leader of Robotics Application Major (Group) as an example, trying to analyze it from the perspective of educational philosophy.
\end{abstract}

From the perspective of educational philosophy, this paper systematically defines the connotation of professional (Group) leaders in vocational colleges, and takes the leader of robotics application (Group) as an example to systematically analyze what the professional (Group) leaders are, what they do and how they do it. Keywords: Higher vocational education, Professional (Group) leader, Robot technology application

\section{WHAT IS THE PROFESSIONAL (GROUP) LEADER}

\section{1. "People" of Professional (Group) Leaders}

From the perspective of educational philosophy, the understanding of human beings has five attributes: one is possibility and generativity, which means that human nature is constantly generated in their own activities and is a kind of "self-regulation". The second is autonomy and creativity, which means that people can not only learn, but also ask questions, explore and innovate. The third is practicality and development, which means that people can continuously self-deny, self-surpass and self-realize through purposeful and conscious independent creative activities. The fourth is the historicity and reality, which means that the human self-essence is gradually generated in the continuous development of history and real life, and is restricted by certain historical and realistic conditions. The fifth is diversity and difference, which means that the possibility of human being as a kind of existence itself contains richness and diversity, and individual life is unique, irreplaceable and different [1].

From the above discussion, it can be seen that, as the professional (Group) leader of higher vocational education, the first thing to be satisfied is the basic attribute of the people in pedagogy, who can self-regulate and self-develop, influenced by the historical environment, different majors and different stages, etc., have their unique temperament and style, especially can lead the team to apply, discover, explore and innovate.

\section{2. "Head" of Professional (Group) Leaders}

The reason why the leader of a major (Group) is the "head" is that, in the construction of a major (Group) and a teaching team, what aspects should be the "head" and what is the difference between the "head" of the party and government leaders? In my opinion, professional (Group) leaders can be "head" from the following five aspects: First, the concept of education and teaching should be held high. As the professional (Group) leader of higher vocational education, the first thing is to have modern advanced and unique vocational education teaching concept, and to have education and teaching methods in line with the development of higher vocational students. According to the characteristics of vocational education and the growth and personality of students, how to adopt appropriate education and teaching strategies? For the robotics major, we should make full use of the product and application characteristics of robots, such as: "sound, light, electricity", "interesting, fun", etc. so that students can learn and learn by doing. The second is to become a "leader" in teaching and educating people. Personnel training is the primary responsibility and core task of higher vocational colleges, and also the ultimate goal of professional construction. Therefore, as a professional (Group) leader, we should fully study the teaching laws of higher vocational education and the characteristics of 
students' growth, and become an example of our major (Group) in terms of teaching and education. We should be able to study teaching and education from school perspective, industry perspective, student development perspective, regional economic perspective, especially from the perspective of "educating talents for the party, selecting talents for the country", and so on. We should also conduct curriculum teaching and practice In the process of teaching, we should fully study the law of Ideological and political education, the law of teaching and education, the law of students' growth and development, etc., and apply them to the practice of teaching and education. We should set an example and set an example to become the "leader" of teaching and education. Third, scientific research and technical services should be "stubborn". Scientific and technological research and social service are the important responsibilities of higher vocational colleges, as well as the premise and foundation of whether professional design and professional teaching can adapt to the development of the times and industrial upgrading. For higher vocational colleges, science and technology research and social services are undoubtedly challenging and difficult. For robotics application, robot is a typical optical mechanical and electrical integration product, which involves a wide and deep range of disciplines and its application is extremely extensive. Moreover, it is necessary to have a deep understanding of the application subdivision field. The main research directions of robot are: multi-sensor Information fusion, control system and its control algorithm, video processing and visual servo control, human-computer interaction, machine learning, communication technology and multi robot coordination, etc. Therefore, as a professional (Group) leader, we should have the spirit of research and deep courage, certain methods, especially the toughness, and become an unyielding "stubborn head" in scientific research and technical services. Fourth, innovation and entrepreneurship guidance should have "fist". Innovation and entrepreneurship guidance is an important aspect of professional construction and teaching in higher vocational colleges. The application of high and new technology and cultural creativity are the key points of innovation and entrepreneurship in Colleges and universities. As professional (Group) leaders, they should have their own views, perspectives, entry points and breakthroughs in innovation and entrepreneurship. Robot and its application are typical representatives of high and new technology, involving all aspects of national life and intelligent manufacturing. It is a good idea or breakthrough to break through technology itself or to apply robot or its key technology to a certain subdivision field. If innovation and entrepreneurship can be carried out in combination with traditional culture, it is a breakthrough. For example: robot themed restaurant, robot assisted the elderly and disabled, UAV entrepreneurship projects in agriculture, transportation and other fields are very successful typical cases. Fifthly, team growth and development should establish a "pole head". Teaching team is not only the designer and implementer of professional construction, but also one of the core factors that affect the quality of personnel training and professional construction. Leading the team to grow together is one of the core responsibilities of professional (Group) leaders. The professional (Group) leader should be the benchmark to lead the team's growth, the model of the team, and the core and soul of the team. As the leader of robot specialty (Group), we should become the "pole head" of robot scientific research and technical service in robot team, and become the demonstration and benchmark of team growth.

\section{3. "Leadership" of Professional (Group) Leaders}

The professional (Group) leader's "leadership" personal view: first, the team's ethics demonstration. The second is the team and students' ideological solution. The third is the technical solution of the team. The professional (Group) leaders should have several brushes. Fourth, the professional (Group) leader should be the leader of team action. Fifth, the professional (Group) leaders should have teaching responsibilities.

\section{4. "Main Business" of Professional (Group) Leaders}

The "main business" of the professional (Group) leaders is that: first, from the aspect of work content: Taking Hunan College of Information as an example, as the representative of the main business vocational colleges with information technology characteristics, "information perception, information processing, information application" is the overall characteristics and strengths of the college. Therefore, as a professional (Group) leader, one is to undertake the main business of higher vocational education; the other is to undertake the main business of information technology; the third is to undertake the main business of robot application in intelligent manufacturing; the fourth is to undertake the main business of cultural heritage and innovation, especially the main business of robot and artificial intelligence culture and innovation. The second level is that we should be dedicated and happy to work in terms of work attitude, establish and prosper in terms of work objectives, and cultivate and start businesses in terms of work process.

\section{5. "Specialty" of Professional (Group) Leaders}

"Specialty" has two meanings: one is simple, unique and concentrated on one thing; the other is to master and possess alone [2]. As the leader of a major (Group), "specialty": first, the direction of scientific and technological research should be specific, which should be vertical and deep in a certain field, with its own expertise; second, the persistence of pursuit, which should adhere to the in-depth development in a specific field, not one 
direction today, but another place tomorrow; third, the leadership of achievements, as the leader of a major (Group), teaching and research Academic achievements must be leading, able to use advanced education and teaching concepts, combined with regional economic and industrial characteristics, and the school's strengths in the field. The research direction of professional (Group) leaders should be specific, persistent in academic pursuit, leading in teaching research and scientific and technological achievements, forward-looking in teaching and education concepts, lasting in teaching actions and creative in academic achievements.

To sum up, professional (Group) leaders should have noble political quality, professional moral quality and rigorous and decent style of study; they should have profound academic purpose and active academic thought, step into the forefront of a professional field, have outstanding professional research direction, and have made creative teaching and scientific research achievements with certain academic level, and be able to organize and lead young teachers The top talents in professional construction. The professional (Group) leader is a kind of academic title and qualification, which can also be used as a job and post requirement.

\section{WHAT DO PROFESSIONAL (GROUP) LEADERS DO}

Professional (Group) leaders take the lead in their work: first, professional design, mainly including: professional optimization and adjustment research; professional training specifications; professional training program. Second, professional planning, including: overall planning of professional development; construction planning of practice base; development planning of professional team. The third is professional guidance, including: curriculum system implementation guidance; curriculum standard design guidance; industry education integration practice guidance. Fourth, team building, including: Based on professional development and scientific research service ability improvement; based on "mentoring" team young teachers' growth; based on "project driven" team building strategy. Based on "project driven, nine dimensional integration", team building is carried out from nine aspects, including scientific research and technical services, study and reform research, curriculum resource development, innovation and entrepreneurship guidance, professional association guidance, skills competition guidance, teaching operation implementation, information construction, international exchange and cooperation.

\subsection{What Professional (Group) Leaders Should Do}

Professional (Group) leaders work mainly from the following five aspects: first, professional research report. Including: (1) organize the design of professional talent demand survey table and Research on typical enterprises; (2) organize the writing of regional industrial talent demand report. Second, talent training program. Including: (1) determine the talent training objectives, training specifications, comprehensive professional ability and development ability of core posts, key and core technology; (2) design curriculum system, write talent training program, cultivate and summarize the characteristics of talent training program. The third is the integration of industry and education. Including: (1) put forward suggestions to improve the construction of practice base; (2) based on the "production, learning and research" of school enterprise cooperation. Fourth, the construction of teaching team. Including: (1) to put forward plans and suggestions for the improvement of the professional team (training, scientific research, teaching and research, technical services, etc.); (2) to guide the young teachers of the major to "help" the improvement of their professional ethics and professional ability. Fifth, scientific research, teaching and research guidance. Including: (1) research new theories, new technologies, new processes, new equipment, new methods and new business forms of the major, organize academic lectures for teachers and students of the major or for foreign countries; (2) study the learning behavior characteristics of students of the major in the intelligent era, and put forward new educational ideas and feasibility suggestions such as educational research, information and internationalization. Sixth, the development of teaching resources. Including: (1) organizing and guiding the development of teaching materials and information-based teaching resources; (2) organizing and guiding skills competitions, professional associations and teaching resources development.

\section{OUR PRACTICE AND EXPERIENCE}

Hunan College of information has made certain construction and exploration in the construction of professional (Group) leaders. At the college level, it has established "five blue" engineering systems such as "Cyan-blue" project and other "mentoring" systems. In the professional (Group) construction, the professional (Group) leaders of the College of electronic engineering have played an active role with outstanding achievements. In the establishment of the provincial key construction projects of Vocational Education in Hunan Province, there are 1 provincial discipline leader and 1 provincial famous teacher People, 1 provincial famous teacher in FURONG famous teacher in Vocational Education of mechanical and electrical industry, 2 provincial professional leaders, 1 provincial teaching team (Application of Electronic Technology), 2 municipal teaching teams (industrial robots, intelligent robots), 1 provincial key internship training base (application of Electronic Technology), 2 provincial excellent majors (electronic information industry) Cheng Technology), a provincial demonstration specialty (Application of electronic technology, electronic information engineering technology), a provincial modern apprenticeship pilot project (industrial robot technology), a 
provincial pilot project for the connection of secondary and higher vocational education (Electronic Information Engineering Technology), a municipal demonstration specialty group (robot technology application specialty group), especially the national model Party branch in 2019 Ministry, provincial model Party branch and two "double leaders"; in the past five years, it has set up more than 30 projects and technical services at or above the provincial level, published more than 200 research papers, published more than 60 invention patents, utility model patents and computer software copyrights, won 2 second prizes of Provincial Teaching Achievement Awards, participated in 1 second prize of national teaching achievement award, participated in skill competition and innovation at or above the provincial level There are 500 winners in the new entrepreneurship competition, 6 provincial excellent resources open courses and 3 municipal level courses.

\section{CONCLUSION}

From the perspective of philosophy of education, this paper systematically analyzes and introduces the connotation of professional (Group) leaders and the conditions of professional (Group) leaders in higher vocational colleges, and defines the main responsibilities of professional (Group) leaders and the real effectiveness of professional (Group) leaders in terms of professional (Group) construction and personnel training, scientific research, technical services, etc.

\section{ACKNOWLEDGEMENT}

This research was financially supported by Hunan Province 2019 FURONG famous teacher construction project (Project No.: XJT [2019] No. 261)

\section{REFERENCES}

[1] Baidu Encyclopedia: person. [EB / OL] https://baike.baidu.com/item/person/13020851

[2] Baidu Encyclopedia: special. [EB / OL] https://baike.baidu.com/item/special/6587296? Fr = Aladdin 